\title{
||||||||||||||||||||||||||||||||||||||||||||||||||||||||||||||||||.
}

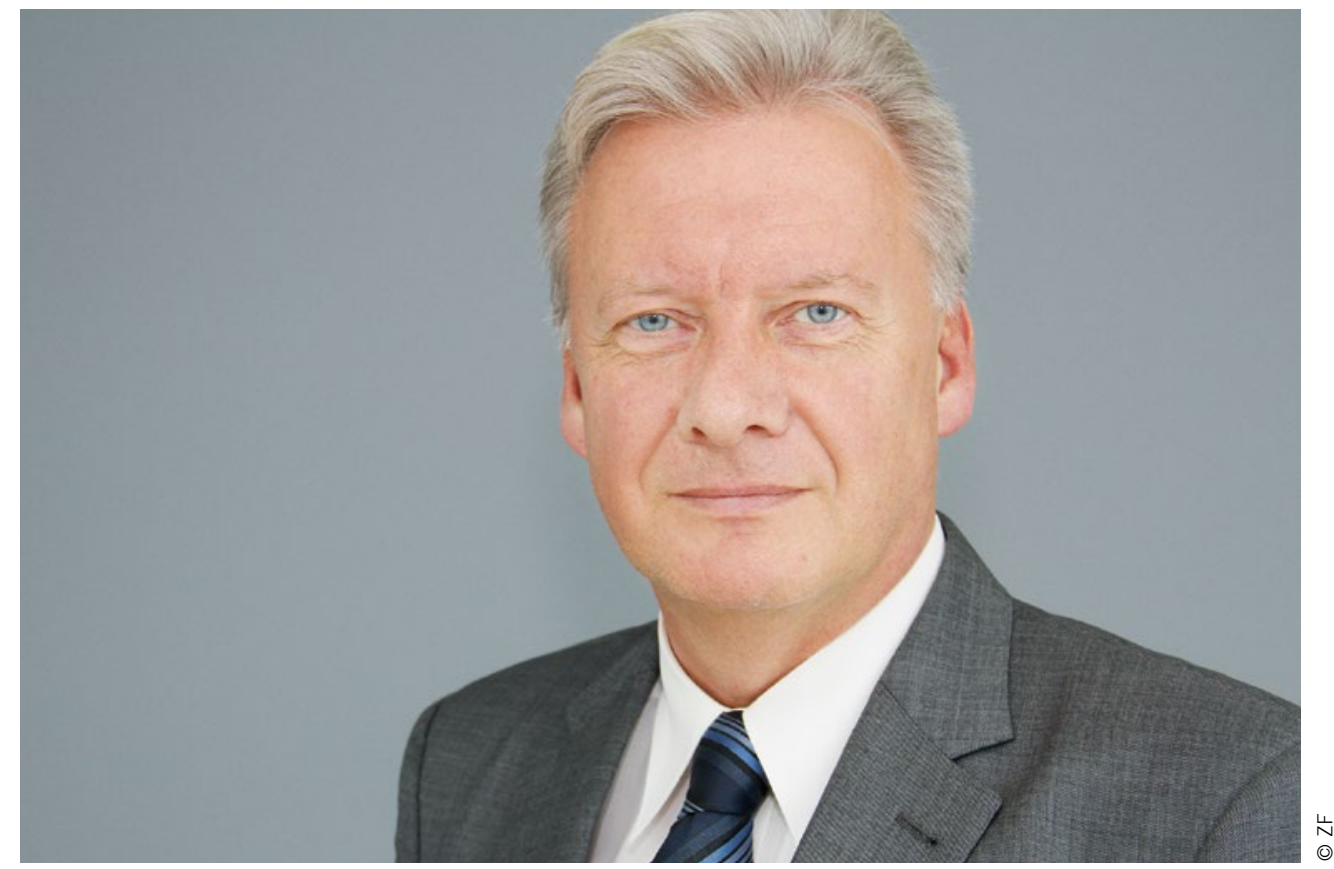

Udo Kneitz

Senior Vice President Industrial Technology and Off-Highway Systems at ZF Friedrichshafen AG in Passau (Germany)

\section{Intelligent Mechanical Systems}

Nowadays, digitalisation and networking have become an indispensable part of our daily lives. In the days of smartphones, we publish content via social media and clouds, and we can also retrieve content via the same channels. The functions of our cars are becoming more and more intelligent, to make specific tasks easier for us, so that we can drive more safely. Electrification and autonomous driving in passenger cars and commercial vehicles will soon be reality. These trends are noticeable in the fields of material handling, construction and agricultural machinery as well. Here too, we are working on market-oriented solutions.

The accelerating trend towards urbanisation is another important driver in our efforts to develop emission-free, more efficient drive systems in the off-highway sector. In the future, machines will be used less to build up new infrastructures in urban centres and more to conserve and repair existing structures. Ultimately, the technologies concerned will also have to evolve in response to pressure from governments and authorities so that we can work in cities without noise and emissions in the future. Yet despite these considerations, conventional drive solutions will still remain a key factor in our markets for a long time. Electric and automated vehicles will gradually establish themselves in parallel with conventional technologies - we see this development as a logical evolution, not as an abrupt revolution.

Our customers are thinking and behaving in more global terms all the time. They expect their suppliers to adopt the same strategy for a worldwide presence and to adapt their products to market requirements flexibly and rapidly. In order to meet the challenges of unceasing competition as well as increasing customer requirements, we must develop modular systems, so that we can likewise achieve the desired technology level.

In the first step, the efficiency and productivity of all drive components can be further optimised. In this regard, automation will play a key role as well as CVT technology in fulfilling the future requirements of the markets. In the second step, we see electrification and autonomous driving as the megatrends in passenger transport that will also be employed in many applications in the off-highway sector as well. Together with our customers, we are in a position to shape this future and develop high-performance, intelligent systems - electric and autonomous systems as well as mechanical systems. This therefore demands new products, and of course innovative production methods as well, to enable us to respond appropriately to these global technology trends.

It is our declared objective to use groundbreaking new technologies and functions to make our customers' vehicles more efficient, safer and easier to maintain. In the ZF Industrial Technology Division, we will also actively leverage the potentials that may be derived from the use of artificial intelligence and correlating big data and deep learning applications. This will enable us to continually increase our flexibility, our creative energies and our speed of innovation for the benefit of the customers. 